\title{
Iatrogenic Damage to the Periodontium by Chemicals and Dental Materials
}

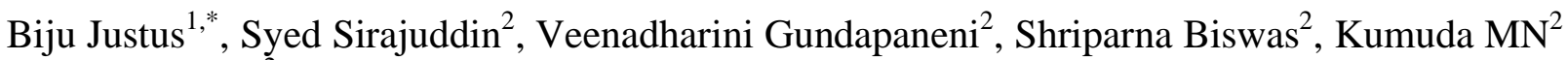 \\ and Rakesh $\mathrm{MP}^{2}$
}

\author{
${ }^{1}$ Al Shamil Medical Centre, P.O. Box 151045, Samnan, Sharjah, UAE; ${ }^{2}$ Department of Periodontology, Rajarajeswari \\ Dental College \& Hospital, Bangalore, Karnataka, India
}

\begin{abstract}
The toxicity and tissue reactions to dental materials are receiving more attention as a wide variety of materials are used and as federal agencies demonstrate more concern in this area. A further indication of the importance of the interaction of materials and tissues is the development of recommended standard practices and tests for the biological interaction of materials.
\end{abstract}

Keywords: Chemicals, dental materials, iatrogenic, periodontium.

\section{INTRODUCTION}

Reactions in the oral soft tissues such as gingival may be caused by restorative materials.

At present, it is not clear to what extent the in vivo cytotoxicity observed is caused by the restorative materials and to what extent the by products of bacterial plaque that accumulate on teeth and restorations.

The general conditions that promote retention of plaque, such as rough surfaces or open margins, increase the inflammatory reactions in gingiva around these materials. However, released products of restorative materials also contribute either directly or indirectly to this inflammation, particularly in areas where the washing effects of saliva are less, such as in interproximal areas, in deep gingival pockets, or under removable appliances.

Several studies have documented increased inflammation or recession of gingiva adjacent to restorations where plaque indexes are low. In these studies, released products from materials could cause inflammation in the absence of plaque or could inhibit formation of plaque and cause inflammation in gingiva [1]. Some basic research has been done in vitro that shows, in principle, that components from dental materials and plaque may synergize to enhance inflammatory reactions.

Some cytotoxicity is exhibited by cements in the recently set state, but this declines substantially with time. The buffering and protein-binding effects of saliva acts to mitigate against the cytotoxic effects [2].

In vitro tests have revealed that direct initial contact of composites with fibroblasts is very cytotoxic. This cytotoxicity is primarily from un-polymerized components in the airinhibited layer that leach out from the materials [3]. Other in vitro studies, which had 'aged' composites in artificial saliva

*Address correspondence to this author at the Al Shamil Medical Centre, P.O. Box 151045, Samnan, Sharjah, UAE; Tel: 00971503619283;

E-mail: bijujustus@gmail.com for up to six weeks, have shown that the toxicity diminishes in some materials but remains high for others [4]. Controversial data are available on the effects of composite resin restorations on gingival health. Larato et al. reported that composite resin restorations adjacent to subgingival class $\mathrm{V}$ cavities leads to gingival inflammation [5]. Similarly, Willershausen et al. reported a high prevalence of gingival bleeding and an increased PD in association with resin- based restorations, as compared with other restorative materials [6].

However, van Dijken et al. reported a significantly higher rate of gingival inflammation when observing 3-4year-old composite resin restorations. This observation was explained by the surface deterioration with a consequent increase in plaque accumulation that occurs in composite resin restorations after in vivo wear, [7].

Casting alloys have a long history of in vivo use with a generally good record of biocompatibility. Some questions about the biological liability of elemental release from many of the formulations developed in the past 10 years have arisen, but there is no clinical evidence that elemental release is a problem, aside from hypersensitivity.

Nickel allergy is a relatively common problem, occurring in $10 \%$ to $20 \%$ of females, and is a significant risk from nickel-based alloys because release of nickel ions from these alloys is generally higher than for high-noble or noble alloys. Palladium sensitivity has also been a concern in some countries, although the incidence of true palladium allergy is one third that of nickel allergy. However, it has been clinically documented that patients with palladium allergy are virtually always allergic to nickel. The converse is not true however. In vitro, there have been numerous articles published on the effects of metal ions on cells in the gingival tissues, such as epithelial cells, fibroblasts, and macrophages.

For the most part, the concentrations of metal ions required to cause problems with these cells in vitro are greater than those released from most casting alloys. However, the most recent research has shown that prolonged exposures to low doses of metal ions may also have biological liabilities. 
These new data are noteworthy because the low-dose concentrations approach those known to be released from some alloys.

The clinical significance of this research is not known, however. Immune hypersensitivity reactions of gingiva and mucosa have been associated with denture base materials, especially methacrylates, (Fig. 1) probably more than any other dental material. Dental and laboratory personnel who are exposed repeatedly to a variety of unreacted components are at greatest risk for hypersensitization.

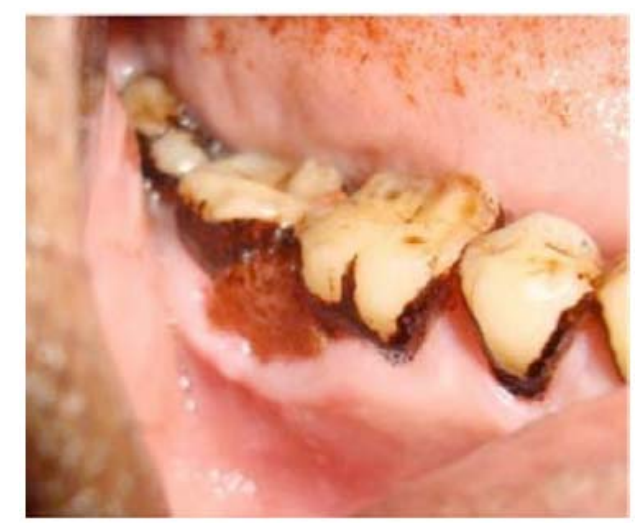

Fig. (1). Immune hypersensitivity reactions tomethacrylates.

Acrylic and diacrylic monomers, certain curing agents, antioxidants, amines, and formaldehyde have been documented to the hypersensitivity reactions. For the patient, however, most of these materials have reacted in the polymerization reaction, and the incidence of hypersensitization is quite low. In addition to hypersensitivity, visible light-cured denture base resins and denture base resin sealants have been shown to be cytotoxic to epithelial cells in culture.

Soft tissue responses to denture liner materials are of concern because of the intimate contact between soft denture liners and the gingiva. In vivo and in vitro release of plasticizers, which are incorporated into some materials to make them soft and flexible leads to soft tissue reactions. Cell culture tests have shown that some of these materials are extremely cytotoxic and affect cellular metabolic reactions. In animal tests, several of these materials presumably from the released plasticizers have caused significant epithelial changes.

In usage, the effects of the released plasticizers are probably often masked by the inflammation already present in the tissues onto which these materials are placed. Denture adhesives have been evaluated in vitro and show severe cytotoxic reactions. Several had substantial formaldehyde content. The adhesives also allowed significant microbial growth. Newer formulations that add antifungal or antibacterial agents have not yet been shown to be clinically efficacious.

\section{REACTION OF SOFT TISSUES AND BONE TO IM- PLANT MATERIALS}

Ceramics, carbon, metals, and polymers (and combinations of the above) are the four basic materials used in implant fabrication: In the past 10 years, the use of implants in clinical practice has increased dramatically and hence the Interest in the biocompatibility of these implant materials. Most successful dental implant materials either promote osseointegration (an approximation of bone on the implant within $100 \mathrm{~A}$ of the implant) or bio-integration (a continuous fusion of bone with the implant).

\section{Reactions to Ceramic Implant Materials}

Most ceramic implant materials are in an oxidized state or are corrosion resistant and thus have very low toxic effects on tissues. As a group, they are non-carcinogenic, nonimmunogenic and have low toxicity. However, they have been used as porous or dense coatings on metals or other materials because they are brittle and lack impact and shear strength. The implants often become firmly bound to bone (through ankylosis or bio-integration), especially if the root surface porosities are more than $150 \mathrm{pm}$ in diameter and if they are taken out of occlusion for a time. However, the tissue usually forms only fibrous in growth if the porosities are smaller. Dense ceramics are also used as root replicas or bone screws. Made of either single crystal (sapphire) or polycrystalline aluminum oxide, they become bio-integrated and provide excellent stability if left unloaded for a time. In one study, $60 \%$ of them restorations still performed adequately after 6 years in place.

Hydroxyapatite, a relatively non-resorbable form of calcium phosphate, has been used with some success as a coating material for titanium implants and as a ridge augmentation material. Studies indicate that the hydroxyapatite increases. However, the long-term corrosion of these coatings and the stability of the bond of the coating to the substrate are still controversial. Retrieval evidence indicates that even these "non-resorbable" coatings are resorbed over the long-term.

Beta-tricalcium phosphate, another form of calcium phosphate, has been used in situations where resorption of the material is desirable, such as repair of bony defects. Carbon has been used as a coating and in bulk forms for implants. Although the biologic response to carbon coatings can be favorable, they have been supplanted by titanium, aluminum oxide bulk materials, and hydroxyapatite coatings. Finally, bioglass forms a surface gel that reacts favorably with connective tissue, allowing bone formation adjacent to it.

\section{Reactions to Pure Metals and Alloys}

The oldest type of oral implant materials are pure metals and alloys and all metal implants share the quality of strength. Initially, metallic materials were selected on the basis of ease of fabrication. Over time, however, biocompatibility with bone and soft tissue and the longevity of the implant have become more important. A variety of implant materials including stainless steel, chromium-cobaltmolybdenum, and titanium and its alloys have been used. These materials have been used in a variety of forms, including root forms and sub-periosteal and trans- osteal implants.

In dentistry, titanium alloys are currently the most commonly used metallic implant materials. Initially when first cast, titanium is a pure metal. The surface forms a thin film of various titanium oxides in less than a second which is corrosion resistant and allows bone to osseo-integrate. Diffi- 
culty in casting is the major disadvantage of this metal. It has been wrought into endosteal blades and root forms, but this process introduces metallic impurities into the surface that may adversely affect bony response unless extreme care is taken during manufacturing. Titanium implants have been used with success asroot forms that are left unloaded under the mucosa for several months before they are used to support a prosthesis. With frequent recall and good oral hygiene, the implants have been maintained in healthy tissue for up to 2 decades.

Titanium-aluminum-vanadium alloys (Ti6A14V) have been used successful in this regard as well, but questions remain about the liability of released aluminum and vanadium. Clinical studies have been positive. Although titanium and titanium alloy implants have corrosion rates that are markedly less than other metallic implants, they do release titanium into the body.

In the soft tissues, the bond which the epithelium forms with titanium is morphologically similar to that formed with the tooth, but this interface has not been fully characterized. Connective tissue apparently does not bond to the titanium, but does form a tight seal that seems to limit ingress of bacteria and bacterial products. Techniques are being developed to limit down growth of the epithelium and loss of bone height around the implant, which ultimately cause implant failure.

A well-documented disease around implants is periimplantitis and it involves many of the same bacteria as periodontitis. The role of the implant material or its released components in the progression of peri-implantitis is not known [8].

\section{The Effects of Guttapercha on Periodontium}

The use of techniques which use vertical condensation of warm gutta-percha during the obturation phase offer a higher probability of closure of the lateral and accessory canals [9]. At the same time however, warm vertical compaction techniques also result in a greater risk of the obturation material being extruded into peri-radicular tissues [10]. Authors have reported significant cytotoxicity of both commonly used cements, and gutta-percha following research studies carried out in vitro with SEM (scanning electron microscope) [11]. This cytotoxicity can induce peri-radicular inflammation, or necrosis of the periodontal ligament, and for this reason over-filling should be avoided as much as possible because it can lead to failure of short term treatment or a negative long term prognosis [12].

Over-instrumentation, in particular, may extrude infected material contained in the canals beyond the apex, interfering, or impeding the healing process of the periapical tissue. Guttapercha cones which had been extruded past the apices and subsequently examined under a scanning electron microscope, have demonstrated the presence of a "biofilm" on the cones [11]. This "biofilm" allows undisturbed growth of the bacteria and renders them particularly resistant to the defences of the host, and may be responsible for foreign body reactions. The consequences of overfilling can, therefore, result in infective periapical periodontitis caused by the transport of bacteria beyond the apex and an incomplete cleansing; foreign body reactions; and pain symptoms which are ascribable to irritative stimuli, even in the absence of radiological evidence [13].

\section{The Effect of Eugenol on Periodontium}

For over a century oil of cloves (eugenol in its unrefined form) has been a popular remedy for toothache. Its therapeutic uses and its mixture with zinc oxide to form a plastic mass were described by Chisholm in 1873. It has antibacterial properties as well as sedative and anodyne effects $[14,15]$. Eugenol is found as a major ingredient in a variety of dental materials such as impression materials, filling materials, dental cements, endodontic sealers, periodontal dressing materials and dry socket dressings.

These materials rely on a setting reaction between zinc oxide and eugenol, which produces zinc eugenolate. This substance however is not stable in the presence of water. The surface of the set material readily undergoes hydrolysis with the release of free eugenol. This release is initially rapid and then decreases exponentially, as all the surface eugenol is hydrolysed.

Eugenol- containing materials are not used in conjunction with composite luting cements or resin composite restorative materials as the free eugenol can interact with other dental materials [16]. Free eugenol can also be harmful to human soft tissues (Fig. 2). Adverse effects of eugenol in the oral cavity have been reported in association with its use in surgical and periodontal packs [17], root canal sealers [18], mouth rinses [19], and in impression pastes [20]. Adverse reactions to eugenol amongst dental personnel have also been reported ranging from localised irritation of the skin to allergic contact dermatitis [21].

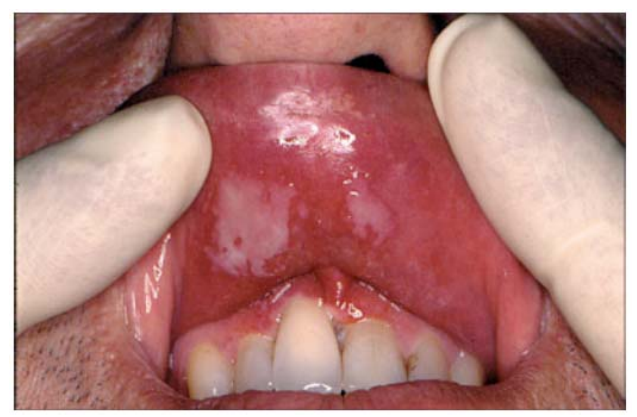

Fig. (2). Erythema and ulceration on the inner surface of the upper lip and around the gingival margincaused by Eugenol.

The type and extent of oral soft tissue reactions to eugenol differ, but can be of in three ways: 1. Eugenolhas an adverse effect on fibroblasts and osteoblast-like cells and is generally cytotoxic at high concentrations [22]. Thus it produces necrosis and reduced healing at high concentrations. This effect will possibly affect all patients and is dose related. 2. Eugenol can act as a contact allergen evoking a localised delayed hypersensitivity reaction in lower concentrations, [23]. 3. When placed in the mouth, eugenolcan sometimes cause a more significant generalised allergic response [24].

\section{Chlorhexidine}

Chlorhexidine $(\mathrm{CHX})$, is a cationic bisbiguanide which has a broad antimicrobial spectrum. It has been proven as the most effective agent against plaque many times. It is used alone or as an adjunct to mechanical cleaning procedures. Its effectiveness for control of gingivitis was also shown in 
long-term studies. The major advantage of CHX over most other compounds lies in its substantivity. After application of a formulation, it binds to soft and hard tissues in the mouth, enabling it to act over a long period [25]. After single rinse bacterial counts in saliva consistently drop to between $10 \%$ and $20 \%$ of baseline and remain at this level for $\geq 7$ hours [26] and probably $>12$ hours [27]. Therefore, $\mathrm{CHX}$ is considered as the gold standard and is used as a positive control in many clinical trials of new mouth rinse formulations.

Continuous use of products containing chlorhexidine for longer periods can cause stains on teeth, tongue, and gingiva and also on silicate and resin restorations; persistent use can also reduce the bitter and salt taste sensations - this latter symptom can be reversed by stopping the use of chlorhexidine [28]. The brownish discoloration of teeth and tongue is because of the disintegration of bacterial membranes, leading to the denaturation of bacterial proteins [29]. At the same time, disulfide functions are reduced to thiol functions [30] that form dark complexes with iron ions found in the saliva.

Mouthwashes containing chlorhexidinethat stain teeth less than the classic solution have been developed, many of which comprise chelated zinc [31]. According to some studies, chlorhexidinegluconate has not been proven to reduce subgingival calculus and in some studies actually increased the deposits. A synergistic effect has been observed to enhance efficacy when chlorhexidine is combined with xylitol, [32]. Common toothpaste additives such as sodium lauryl sulfate and sodium monofluorophosphate neutralize chlorhexidine. Although data are limited, it may be best to keep more than a 30-minute interval between brushing and using the mouthwash, cautiously close to 2 hours after brushing to maximize the effectiveness of chlorhexidine [33].

Surface etching by various chemical products with toxic properties may result in mucosal reactions including reactions of the gingiva. Chlorhexidine induced mucosal desquamation (Fig. 3) [34] acetylsalicylic acid burn [35], cocaine burn [36], and slough due to dentifrice detergentsare examples of such reactions [37]. These lesions are reversible and resolve after quitting the toxic influence. Improper use of caustics by the dentist causes chemical injury to the gingival tissues. If the cavity sealing is insufficient, paraformaldehyde used for pulp mummification may give rise to inflammation and necrosis of the gingival tissues [38]. Generally, the diagnosis is evident from the clinical findings and patient history.

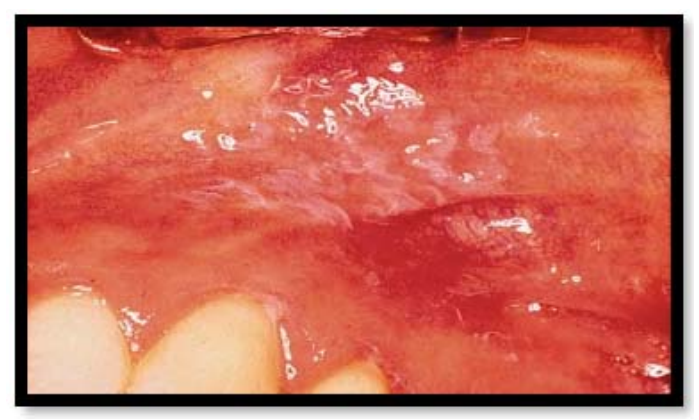

Fig. (3). Chlorhexidine-induced mucosal desquamation. This is a reversible type of lesion, which is completely normalized after stopping chlorhexidineuse.

\section{CONCLUSION}

The biocompatibility of dental material depends on its location, composition, and interactions with the oral cavity. Metal, ceramic, and polymer materials elicit different biological responses because of their differences in composition. Furthermore, varied biological responses to these materials are determined by the release of their components and whether these components at their released concentrations are toxic, immunogenic, or mutagenic. The biocompatibility of a material is partially determined by its location in the oral cavity. Materials that appear biocompatible when in contact with the oral mucosal surface may cause adverse reactions if they are implanted beneath it. Features of a material's surface that promote or discourage the attachment of bacteria, host cells, or biological molecules determine whether the material will promote plaque retention, integrate with bone, or adhere to dentin.

\section{CONFLICT OF INTEREST}

The authors confirm that this article content has no conflict of interest.

\section{ACKNOWLEDGEMENTS}

Declared none.

\section{REFERENCES}

[1] Arne Hensten-Pettersen. Adv Dent Res 1992; 6(1): 38-43.

[2] Schmid-Schwap M, Franz A, König F, et al. Cytotoxicity of four categories of dental cements, Dent Mater 2009; 25(3): 360-8.

[3] Darmani H, Al-Hiyasat AS, Milhem MM, Cytotoxicity of dental composites and their leached components, Quintessence Int 2007; 38(9): 789-95.

[4] Goldberg M. In vitro and in vivo studies on the toxicity of dental resin components: a review. Clin Oral Investig 2008; 12(1): 1-8.

[5] Larato DC. Influence of a composite resin restoration on the gingiva. J Prosthet Dent 1972; 28: 402-40.

[6] Willershausen B, Köttgen C, Ernst CP. The influence of restorative materials on marginal gingiva. Eur J Med Res 2001; 6: 433-9.

[7] Dijken JWV, van Sjostrom S, Wing K. The effect of different types of composite resin fillings on marginal gingiva. J Clin Periodontol 1987; 14: 185-9.

[8] Craig GR. Restorative Dental Materials. $11^{\text {th }}$ ed. Mosby 2002; pp. 126-55.

[9] Dulac KA, Nielsen CJ, Tomazic TJ, et al. Comparison of the obturation of lateral canals by six techniques. J Endod 1999; 25(5): 37680.

[10] Al-Dewani N, Hayes SJ, HowellDummer PM. Comparison of laterally condensed and low temperature thermo plasticized guttapercha root fillings. J Endod 2000; 26(12): 733-8.

[11] Gutierrez JH, Brizuela C, Villota E. Human teeth with periapicalpathosis after over instrumentation and overfilling of the root canals: a scanning electron microscopic study. Int Endod J 1999; 32: 40-8.

[12] Pascon A, Leonardo MR, Safovi K, et al. Tissue reactions to endodontic materials: criteria, assessment and observations. Oral Surg Oral Med Oral Pathol Oral Radiol Endod 1991; 72: 222-37.

[13] Bergenholtz G, Lekholm U, Milthon R, et al. Influence of apical over instrumentation and overfilling on retreated root canals. J Endod 1979; 5: 310-4.

[14] Hume WR. The pharmacological and toxicological properties of zinc oxide-eugenol. J Am Dent Assoc 1986; 113: 789-91.

[15] Newman M G, Hulem C, Colgate J, Anselmo C. Antibacterial susceptibility of plaque bacteria. J Dent Res 1979; 58: 1722-32.

[16] Mayer T, Pioch T, Duschner H, Staehle H J. Dentinal adhesion and histomorphology of two dentinalbonding agents under the influence of eugenol. Quintessence Int 1997; 28: 57-62. 
[17] Koch G, Magnusson B, Nyquist G. Contact allergy to medicaments and materials used in dentistry. II. Sensitivity to eugenol and colophony. Odontol Revy 1971; 22: 275-89.

[18] Hensten-Pettersen A, Orstavik D, Wennberg A. Allergenic potential of root canal sealers. Endo Dent Traumatol 1985; 1: 61-5.

[19] Vilaplana J, Grimalt F, Romaguera C, Conellana F. Contact dermatitis from eugenol in mouthwash. Contact Dermatitis 1991; 24: 223-4.

[20] Goransson K, Karltorp N, Ask H, Smedberg O. Nagra fall aveugenol over kanslighet (some cases of eugenol hypersensitivity). Svensk Tandlakaretidskrift 1967; 60: 545-9.

[21] Jacobsen N, Hensten-Pettersen A. Occupational health problems and adverse patient reactions in periodontics. J Clin Periodontol 1989; 16: 428-33.

[22] Lindqvist L, Otteskog P. Eugenol: liberation from dental materials and effect on human diploid fibroblast cells. Scand J Dent Res 1980; 88: 526-52.

[23] Vilaplana J, Grimalt F, Romaguera C, Conellana F. Contact dermatitis from eugenol in mouthwash. Contact Dermatitis 1991; 24: 223-4.

[24] Barkin ME, Boyd JP, Cohen S. Acute allergic reaction to eugenol. Oral Surg Oral Med Oral Pathol 1984; 57: 441-2.

[25] Adams D, Addy M. Mouth rinses. Adv Dent Res 1994; 8: 291-301.

[26] Addy M, Wright R. Comparison of the in vivo and in vitro antibacterial properties of providone iodine and chlorhexidinegluconate mouth rinses. J Clin Periodontol 1978; 5: 198-205.

[27] Schiott CR, Loe H, Jensen SB, Kilian M, Davies RM, Glavind K. The effect of chlorhexidine mouth rinses on the human oral flora. J Periodontal Res 1970; 5: 84-9.
[28] Helms JA, Della-Fera MA, Mott AE, Frank ME. Effects of chlorhexidine on human taste perception. Arch. Oral Biol 1995; 40(10): 913-20.

[29] Hjeljord LG, Rolla G, Bonesvoll P. Chlorhexidine-protein interactions. J Periodontal Res Suppl 1973; 12: 11-6.

[30] Gilbert HF. Molecular and Cellular Aspects of Thiol-Disulfide Exchange. Adv Enzym Related Areas Molecular Biol 1990; 63: 69172.

[31] Bernardi F, Pincelli MR, Carloni S, Gatto MR, Montebugnoli L. Chlorhexidine with an Anti Discoloration System. A comparative study. Int J Dent Hyg 2004; 2 (3): 122-6.

[32] Decker EM, Maier G, Axmann D, Brecx M, von Ohle C. Effect of xylitol/chlorhexidine versus xylitol or chlorhexidine as single rinses on initial biofilm formation of cariogenic streptococci. Quintessence Int 2008; 39(1): 17-22.

[33] Kolahi J, Soolari A. Rinsing with chlorhexidinegluconate solution after brushing and flossing teeth: a systematic review of effectiveness. Quintessence Int 2006; 37(8): 605-12.

[34] Flotra L, Gjermo P, Rølla G. Wærhaug J. Side effects of chlorhexidine mouth washes. Scand J Dent Res 1971; 79:119-25.

[35] Najjar TA. Harmful effects of "aspirin compounds". Oral Surgery Oral Medicine Oral Pathology 1977; 44: 64-70.

[36] Dello Russo NM, Temple HV. Cocaine effects on gingiva. J Am Dent Assoc 1982; 104: 13.

[37] Muhler JC. Dentifrices and oral hygiene. In: Bernier JL, Muhler JC, Eds. Improving Dental Practice Through Preventive Measures. St. Louis: CV. Mosby Co 1970; pp. 133-57.

[38] Di Felice R, Lombardi T. Gingival and mandibular bone necrosis caused by a paraformaldehyde-containing paste. Endod Dent Traumatol 1998; 14: 196-8.

\footnotetext{
Received: December 22, 2014

(C) Justus et al.; Licensee Bentham Open.
}

Revised: March 04, 2015

Accepted: March 10, 2015

This is an open access article licensed under the terms of the Creative Commons Attribution Non-Commercial License (http://creativecommons.org/licenses/by-nc/3.0/) which permits unrestricted, non-commercial use, distribution and reproduction in any medium, provided the work is properly cited. 